Nevşehir Bilim ve Teknoloji Dergisi Cilt 5(1) 1-9 2016

DOI: 10.17100/nevbiltek.63192

URL: http://dx.doi.org/10.17100/nevbiltek.63192

\title{
Nevşehir İli Balık Faunası İçin Koruma ve İzleme Programı Önerileri
}

\author{
Erdoğan Çiçek* ${ }^{*}$ Sevil Birecikligil, Selda Öztürk, Burak Seçer, Yasemin Celepoğlu \\ Nevşehir Hacı Bektaş Veli Üniversitesi, Fen Edebiyat Fakültesi, Biyoloji Bölümü, Nevşehir
}

$\ddot{\text { Ozz }}$

Bu çalışma Nevşehir ili balık faunasının belirlenmesi amacıyla Mayıs-Eylül 2014 tarihleri arasında gerçekleştirilmiştir. Elektroşoker ve uzatma ağları kullanılarak yapılan örnekleme çalışmaları sonucunda Cyprinidae, Cyprinodontidae, Cobitidae, Nemacheilidae ve Percidae familyalarına ait 13 takson (Alburnus orontis, Aphanius marassantensis, Capoeta sieboldi, Capoeta tinca, Carassius gibelio, Carassius auratus, Cobitis simplicispina, Cyprinus carpio, Oxynoemacheilus angorae, Sander lucioperca, Seminemacheilus lendlii, Squalius cf. cephalus ve Tinca tinca) elde edilmiştir. Daha önce Kızılırmak'tan rapor edilmiş olan Silurus glanis ve Luciobarbus escherichii, Damsa Baraj Gölü’nde tespit edilmiş olan Oreochromis niloticus ve Atherina boyeri türlerine ise arazi çalışmaları sırasında rastlanmamıştır. Elde edilen bu türler içerisinde 4 tanesinin Türkiye için endemik, 6 tanesinin taşınmış ve 4 tanesinin ise geniş dağılımlı tür olduğu tespit edilmiştir. Bu çalışmada yapılan gözlemler ve elde edilen verilere dayanarak ihtiyofaunal biyoçeşitliliğin korunması ve iyileştirilmesi için gerekli olan izleme önerilerine yer verilmiştir.

Anahtar kelimeler: Kızılırmak Havzası, Nevşehir, ihtiyofauna, endemik, egzotik tür

\section{Suggestions of Conservation and Monitoring Programs for Freshwater Ichthyofauna in Nevsehir}

\begin{abstract}
This study was carried out in order to determine freshwater ichthyofauna of Nevsehir between May and September 2014. A total of 13 fish species have been sampled using electrofisher and gill-nets in Nevsehir province belonging to Cyprinidae, Cyprinodontidae, Cobitidae, Nemacheilidae and Percidae families. These are Alburnus orontis, Aphanius marassantensis, Capoeta sieboldi, Capoeta tinca, Carassius gibelio, Carassius auratus, Cobitis simplicispina, Cyprinus carpio, Oxynoemacheilus angorae, Sander lucioperca, Seminemacheilus lendlii, Squalius cf. cephalus and Tinca tinca. Some species, Silurus glanis and Luciobarbus escherichii inhabits in Kızllırmak, Oreochromis niloticus and Atherina boyeri reported from Damsa Dam Lake have not been sampled during the study period. Of these, 4 are endemic fish species for Turkey, 4 are introduced and others are wide distribution in central area and Kizllırmak River Basin. In this study, based on data obtained from observations made in the fish ihtiyofaunal and biodiversity conservation are given to proposals that are required for monitoring and improvement.
\end{abstract}

Keywords: Kızılırmak River Basin, Nevsehir, ichthyofauna, endemic, exotic species

*e-mail: erdogancicek@nevsehir.edu.tr 


\section{Giriş}

Biyoçeşitlilik, herhangi bir zamanda herhangi bir bölgede bulunan tür sayısı olarak ifade edilmekte olup aynı zamanda bir bölgedeki genlerin, bu genleri taşıyan türlerin, bu türleri barındıran ekosistemlerin ve bunları birbirine bağlayan olayların (süreçlerin) oluşturduğu bir bütündür. Biyoçeşitlilik üzerindeki tehditler günümüzde insanlığın karşılaştığı en ciddi küresel çevre sorunlarından biri olarak kabul edilmektedir [1].

Dünyada kıta özelliği gösteren, birçok türün ana vatanı olan ve Jeolojik devirler boyunca jeolojik ve iklimsel değişikliklerden etkilenen canlılara barınak olan Anadolu, Dünyadaki herhangi bir kara parçasından çok daha fazla biyolojik öneme sahiptir. Ayrıca her türün, Türkiye’nin topoğrafik özelliklerine bağlı olarak çeşitlenmesi nedeniyle, çok sayıda alttür ve ırkla temsil edilmesi, bu zenginliğe artı bir değer daha katmaktadır [2]. Bu önemin kavranması, korunması, iyileştirilerek gelecek nesillere aktarılması gereklidir. Doğal hayatın devamlılı̆̆ı ve korunabilmesi bakımından, ilk ve en önemli adım biyoçeşitliliğin tespit edilmesi sonrasında türlerin izlenmesi ve verilerin saklanması da büyük önem taşımaktadır [3].

Türkiye, Dünyada aynı iklim kuşağında yer alan diğer ülkelerden hem zengin biyolojik çeşitliliği hem de çeşitli genetik farklılaşma alanları bulundurması nedeniyle çok özel bir konuma sahiptir [4]. Nitekim son yapılan yeni tür kaydı bildirimleri ile Türkiye'de iç su balık faunasında endemizm oranının \%40’ları aşmıştır [5].

Tatlı su kaynakları, biyolojik ve ekolojik yönden büyük öneme sahip doğal kaynaklar olup bu ortamda yaşayan canlı türlerinin ve bunların mevcut durumlarının tespit edilmesi gerekmektedir [6]. Gelişmiş ülkelerde tatlı su faunasını belirleme çalışmalarının geçmişi çok eskilere dayanırken, Türkiye'de balık faunası ile ilgili çalışmalar 19. yüzyılda Avrupalı araştırmacılarca başlatılmıştır [7-17]. Alman Bilim Adamı Ord. Prof. Dr. Curt Kosswig'in İstanbul Üniversitesi'nde görev almasından sonra hidrobiyoloji ile ilgili bilimsel çalışmalar büyük bir ivme kazanarak, onun önderliğinde pek çok Türk bilim insanı yetişmiştir [18 ]. Ancak yabancı bilim insanlarının Türkiye biyoçeşitliliğine olan ilgisi halen devam etmektedir [19].

Kızılırmak Havzasında yaşayan balık türlerine ait popülasyon dinamiğini belirlemeye yönelik pek çok çalışma bulunmasına karşın fauna çalışmalarının kısıtlı olduğu görülmüştür [20 ].

Türkiye'nin en büyük nehirlerinden biri olan Kızılırmak, il sınırları içerisinden geçmesine rağmen Nevşehir tatlı su kaynakları bakımından fakir bir özellik sergilemektedir. Şu ana kadar Nevşehir ili balık faunasının belirlenmesine yönelik kapsamlı bir çalışmaya rastlanmamıştır. İldeki barajların bir kısmında yapılmış olan bir fauna çalışmasında 10 takson tespit edilmiştir [21 ]. Bunun yanı sıra Damsa Barajı'nda tropikal iklim balıklarından istilacı bir tür olan Oreochromis niloticus'a rastlandığı rapor edilmiş [22 ] ve 2012 yılında Atherine boyeri’nin varlığı tespit edilmiştir.

Bu çalışmada Ulusal Biyolojik Çeşitlilik Envanter ve İzleme Projesi kapsamında Nevşehir İli’nin Karasal Biyolojik Çeşitlilik ve İç Su Ekosistemleri Biyolojik Çeşitlilik Envanter ve İzleme projesi kapsamında yapılan arazi çalışmaları ve kaynak taramaları sonucunda Nevşehir ili ihtiyofaunası ortaya konarak, biyoçeşitliliğin korunmasına yönelik olarak önerilere yer verilmiştir. 


\section{Materyal ve Yöntem}

Bu çalışma Ulusal Biyolojik Çeşitlilik Envanter ve İzleme Projesi kapsamında Nevşehir İli’nin Karasal Biyolojik Çeşitlilik ve İç Su Ekosistemleri Biyolojik Çeşitlilik Envanter ve İzleme Projesi kapsamında Nevşehir il sınırları içerisindeki 27 akarsu, 8 baraj gölü olmak üzere toplam 35 istasyonda gerçekleştirilmiştir. Yapılan arazi çalışmalarında örnekleme istasyonlarının koordinatları, rakım değerleri ve alanın genel ekolojik özellikleri kaydedilmiştir (Tablo 1). Örnekleme akarsu istasyonlarında elektroşoker (SAMUS 725MP) ve barajlarda ise uzatma ağları kullanılarak yapılmıştır. Elde edilen örneklerin fotoğrafları çekildikten sonra \%4'lük formaldehit içerisinde plastik kaplarda muhafaza edilerek laboratuvara getirilmiştir.

Tablo 1. Örnekleme istasyonlarına ait bilgiler

\begin{tabular}{|c|c|c|c|}
\hline $\begin{array}{c}\text { İstasyon } \\
\text { No }\end{array}$ & Tarih & Mevkii & Koordinat \\
\hline \multicolumn{4}{|c|}{ Akarsular } \\
\hline A-1 & 17.06 .2014 & Sulusaray & $38^{\circ} 42^{\prime} 44^{\prime \prime} \mathrm{K} / 34^{\circ} 50^{\prime} 48^{\prime \prime} \mathrm{D}$ \\
\hline A-2 & 17.06.2014 & Sulusaray & $38^{\circ} 43^{\prime} 47^{\prime \prime} \mathrm{K} / 34^{\circ} 43^{\prime} 57^{\prime \prime} \mathrm{D}$ \\
\hline A-3 & 17.06.2014 & Sulusaray & $38^{\circ} 37^{\prime} 18^{\prime \prime} \mathrm{K} / 34^{\circ} 38^{\prime} 4^{\prime \prime \prime} \mathrm{D}$ \\
\hline A-4 & 18.06.2014 & Avanos & $38^{\circ} 43^{\prime} 23^{\prime \prime} \mathrm{K} / 34^{\circ} 48^{\prime} 94^{\prime \prime} \mathrm{D}$ \\
\hline A-5 & 18.06.2014 & Avanos-Sarıhıdır & $38^{\circ} 38^{\prime} 78^{\prime \prime} \mathrm{K} / 34^{\circ} 48^{\prime} 87^{\prime \prime} \mathrm{D}$ \\
\hline A-6 & 18.06 .2014 & Göynük & $38^{\circ} 48^{\prime} 34^{\prime \prime} \mathrm{K} / 34^{\circ} 55^{\prime} 73^{\prime \prime} \mathrm{D}$ \\
\hline A-7 & 18.06.2014 & Göynük & $38^{\circ} 48^{\prime} 24^{\prime \prime} \mathrm{K} / 34^{\circ} 56^{\prime} 54^{\prime \prime} \mathrm{D}$ \\
\hline A-8 & 18.06.2014 & Göynük & $38^{\circ} 51^{\prime} 69^{\prime \prime} \mathrm{K} / 34^{\circ} 57^{\prime} 63^{\prime \prime} \mathrm{D}$ \\
\hline A-9 & 18.06.2014 & Sarılar & $38^{\circ} 57^{\prime} 37^{\prime \prime} \mathrm{K} / 34^{\circ} 48^{\prime} 28^{\prime \prime} \mathrm{D}$ \\
\hline A-10 & 18.06 .2014 & Çağsak Köyü & $39^{\circ} 04^{\prime} 57^{\prime}, \mathrm{K} / 34^{\circ} 45^{\prime} 28^{\prime}, \mathrm{D}$ \\
\hline A-11 & 18.06.2014 & Pazarcık Kuş Cenneti & $39^{\circ} 03^{\prime} 08^{\prime \prime} \mathrm{K} / 34^{\circ} 45^{\prime} 28^{\prime \prime} \mathrm{D}$ \\
\hline A-12 & 19.06.2014 & Çağsak Köyü & $39^{\circ} 05^{\prime} 19^{\prime \prime} \mathrm{K} / 34^{\circ} 44^{\prime} 67^{\prime \prime} \mathrm{D}$ \\
\hline A-13 & 19.06.2014 & Doyduk Köyü & $39^{\circ} 11^{\prime} 34^{\prime \prime} \mathrm{K} / 34^{\circ} 45^{\prime} 16^{\prime \prime} \mathrm{D}$ \\
\hline A-14 & 19.06.2014 & Doyduk Barajı Çıkışı & $39^{\circ} 12^{\prime} 22^{\prime \prime} \mathrm{K} / 34^{\circ} 44^{\prime} 19^{\prime \prime} \mathrm{D}$ \\
\hline A-15 & 19.06.2014 & Çayiçi Köyü & $39^{\circ} 12^{\prime} 21^{\prime \prime} \mathrm{K} / 34^{\circ} 41^{\prime} 11^{\prime \prime} \mathrm{D}$ \\
\hline A-16 & 19.06.2014 & Yassıca Köyü & $39^{\circ} 13^{\prime} 56^{\prime \prime} \mathrm{K} / 34^{\circ} 39^{\prime} 43^{\prime \prime} \mathrm{D}$ \\
\hline A-17 & 19.06.2014 & Küllüce Köyü & $39^{\circ} 13^{\prime} 75^{\prime \prime} \mathrm{K} / 34^{\circ} 41^{\prime} 47^{\prime \prime} \mathrm{D}$ \\
\hline A-18 & 19.06.2014 & Karasenir Köyü & $39^{\circ} 17^{\prime} 44^{\prime \prime} \mathrm{K} / 34^{\circ} 50^{\prime} 91^{\prime \prime} \mathrm{D}$ \\
\hline A-19 & 19.06.2014 & Karasenir-Kanlıca & $39^{\circ} 17^{\prime} 13^{\prime \prime} \mathrm{K} / 34^{\circ} 53^{\prime} 21^{\prime \prime} \mathrm{D}$ \\
\hline A-20 & 20.06 .2014 & Arıtma Tesisi Yanı & $38^{\circ} 35^{\prime} 82^{\prime \prime}, \mathrm{K} / 34^{\circ} 30^{\prime} 36^{\prime \prime} \mathrm{D}$ \\
\hline A-21 & 20.06.2014 & Gökçetoprak & $38^{\circ} 39^{\prime} 15^{\prime \prime}, \mathrm{K} / 34^{\circ} 18^{\prime} 68^{\prime \prime} \mathrm{D}$ \\
\hline A-22 & 20.06.2014 & Ovaören Köyü & $38^{\circ} 36^{\prime} 09^{\prime \prime} \mathrm{K} / 34^{\circ} 18^{\prime} 50^{\prime \prime} \mathrm{D}$ \\
\hline A-23 & 20.06.2014 & Ovaören Köyü & $38^{\circ} 36^{\prime} 40^{\prime \prime} \mathrm{K} / 34^{\circ} 17^{\prime} 73^{\prime \prime} \mathrm{D}$ \\
\hline A-24 & 20.06.2014 & Yalıntaş Göleti & $38^{\circ} 40^{\prime} 97^{\prime \prime} \mathrm{K} / 34^{\circ} 20^{\prime} 45^{\prime \prime} \mathrm{D}$ \\
\hline A-25 & 20.06.2014 & Hacıbektaş-Ayhan & $38^{\circ} 54^{\prime} 32^{\prime \prime} \mathrm{K} / 34^{\circ} 38^{\prime} 10^{\prime \prime} \mathrm{D}$ \\
\hline A-26 & 20.06.2014 & Cemil Köyü & $38^{\circ} 32^{\prime} 15^{\prime}, \mathrm{K} / 34^{\circ} 55^{\prime} 56^{\prime \prime} \mathrm{D}$ \\
\hline A-27 & 20.06 .2014 & Ürgüp-Mustafapaşa yolu & $38^{\circ} 36^{\prime} 00^{\prime \prime} \mathrm{K} / 34^{\circ} 54^{\prime} 42^{\prime \prime} \mathrm{D}$ \\
\hline \multicolumn{4}{|c|}{ Barajlar } \\
\hline G-1 & 18.09 .2014 & Tatlarin Baraj1 & $38^{0} 36^{\prime} 52^{\prime \prime} \mathrm{K} / 34^{0} 30^{\prime} 15^{\prime \prime} \mathrm{D}$ \\
\hline $\mathrm{G}-2$ & 18.09 .2014 & Yalıntaş Barajı & $38^{\circ} 40^{\prime} 46^{\prime \prime} \mathrm{K} / 34^{\circ} 20^{\prime} 11^{\prime \prime} \mathrm{D}$ \\
\hline G-3 & 19.09.2014 & Ayhanlar Barajı & $38^{\circ} 49^{\prime} 29^{\prime \prime} \mathrm{K} / 34^{\circ} 43^{\prime} 08^{\prime \prime} \mathrm{D}$ \\
\hline G-4 & 19.09.2014 & Kumtepe Baraj1 & $38^{\circ} 55^{\prime} 41^{\prime \prime} \mathrm{K} / 34^{\circ} 37^{\prime} 39^{\prime \prime} \mathrm{D}$ \\
\hline G-5 & 20.09.2014 & Doyduk Barajı & $39^{\circ} 11^{\prime} 54^{\prime \prime} \mathrm{K} / 34^{\circ} 45^{\prime} 14^{\prime \prime} \mathrm{D}$ \\
\hline G-6 & 21.09.2014 & Damsa Baraj1 & $38^{\circ} 32^{\prime} 35^{\prime \prime} \times \mathrm{K} / 34^{\circ} 55^{\prime} 28^{\prime \prime} \mathrm{D}$ \\
\hline G-7 & 22.09.2014 & Taşlıhöyük Barajı & $39^{\circ} 08^{\prime} 03^{\prime \prime} \mathrm{K} / 34^{\circ} 55^{\prime} 08^{\prime \prime} \mathrm{D}$ \\
\hline G-8 & 22.09 .2014 & Özkonak Göleti & $38^{\circ} 51^{\prime} 14^{\prime \prime} \mathrm{K} / 34^{\circ} 51^{\prime} 04^{\prime \prime} \mathrm{D}$ \\
\hline
\end{tabular}

Laboratuvara getirilen örneklerin tür tayinleri yapılmak üzere morfometrik ve meristik özellikleri belirlenmiştir. Bunlardan total boy, çatal boy ve standart boy $0,1 \mathrm{~cm}$ hassasiyetli boy ölçüm tahtası; vücut yüksekliği, göz çapı, baş uzunluğu ise $0,01 \mathrm{~mm}$ hassasiyetli dijital kumpas kullanılarak belirlenmiştir. Meristik karakterlerin (yanal çizgi pul sayısı, yüzgeç 1şın sayısı, farinks dişi vb. gibi) belirlenmesi için ise masa tipi 1şıklı büyüteç ve stereo mikroskoptan yararlanılmıştır. Elde edilen balık örneklerinin tür tayinleri [7 ], [23 ]ve [24 ]'dan yararlanılarak yapılmıştır. 


\section{Bulgular ve Tartışma}

\subsection{Ekosistem Çeşitliliği ve Tespit Edilen Türler}

Nevşehir ilinde akarsu (lotik) ve barajların oluşturduğu durgun su (lentik) ekosistemi olmak üzere iki tip ekosistem tespit edilmiştir. Bunun yanı sıra Pazarcık Kuş Cenneti (A-11) olarak adlandırılan istasyonunun büyük ölçüde özelliğini kaybetmiş olsa da bir sulak alan olduğu tespit edilmiştir. Söz konusu alanla ilgili koruma, kurtarma ve iyileştirme önlemlerinin alınması halinde doğal bir sulak alan ekosistemi haline geleceği düşünülmektedir.

Örnekleme çalışmaları sonucunda Cyprinidae, Cyprinodontidae, Cobitidae, Nemacheilidae ve Percidae familyalarına ait toplam 13 tür tespit edilmiş olup daha önceki çalışmalarda rapor edilmiş veya gözlemlenmiş olan 4 türe ise rastlanmamıştır.

Örnekleme süresince 35 istasyonun sadece 22 tanesinde balık örneğine rastlanmıştır (Tablo 2). İlde en yaygın olan tür 13 istasyonda rastlanmış olan S. cf. cephalus olup bunu 8'er istasyonda rastlanmış olan $C$. tinca ve $C$. carpio türlerinin izlediği belirlenmiştir. C. tinca hem lotik ve hem de lentik ekosistemlerde dağılım göstermekte olup lentik ekosistemlerde ise balıklandırma yoluyla aşılanmış olan C. auratus, C. gibelio ve C. carpio gibi istilacı türlerin baskın olduğu ve hatta G-1 ve G-2 nolu istasyonlarda hiçbir yerli türe rastlanmadığı belirlenmiştir. Balıklandırma yoluyla aşılanmış olan T. tinca ve S. lucioperca ise sadece aşılanmış oldukları Damsa Barajında bulundukları ve başka bir su ortamına dağılım göstermedikleri tespit edilmiştir. Farklı habitatlarda çok geniş yayılım gösteren $S$. cf. cephalus, C. tinca ve $T$. tinca gibi bazı Cyprinidae familyası üyeleri kirli sayılabilecek sucul habitatlarda da yaşayabildiği gibi, değişen ortam koşullarına adaptasyonda başarılı olarak populasyon yoğunluklarını koruyabildikleri görülmüştür.

Tablo 2. İstasyonlara göre türlerin dağılımı (*daha önceki çalışmalarda rapor edilmiş türler)

\begin{tabular}{|c|c|c|c|c|c|c|c|c|c|c|c|c|c|c|c|c|c|c|c|c|c|c|}
\hline & \multicolumn{8}{|c|}{ Barajlar } & \multicolumn{14}{|c|}{ Akarsu İstasyonları } \\
\hline 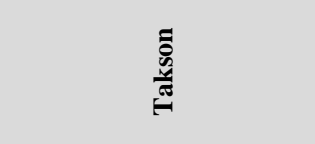 & $\vec{b}$ & $\hat{v}$ & $\dot{b}$ & i & ú & ư & $\hat{j}$ & ij & 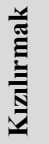 & $\frac{}{\frac{1}{4}}$ & $\frac{7}{2}$ & $\frac{\stackrel{7}{\pi}}{4}$ & $\frac{n}{2}$ & $\frac{\Xi}{\frac{J}{4}}$ & $\frac{5}{\frac{1}{4}}$ & $\stackrel{\infty}{\frac{\pi}{\alpha}}$ & $\frac{9}{\frac{1}{4}}$ & $\underset{\pi}{\stackrel{N}{4}}$ & $\underset{\sim}{*}$ & 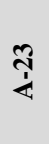 & $\underset{⿱ 亠 乂}{\stackrel{4}{4}}$ & 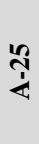 \\
\hline Alburnus orontis & & & & & & & & & & & & & & & & & $\mathrm{X}$ & & & & & \\
\hline Aphanius marassantensis & & & & & & & & & & $\mathrm{x}$ & $\mathrm{x}$ & & $\mathrm{x}$ & & & & & & & & & \\
\hline Atherina boyeri* & & & & & & $\mathrm{x}$ & & & & & & & & & & & & & & & & \\
\hline Capoeta sieboldi & & & & $\mathrm{x}$ & & & & & $\mathrm{x}$ & & & & & & & & & & & & & \\
\hline Capoeta tinca & & & $\mathrm{x}$ & $\mathrm{x}$ & $\mathrm{x}$ & & & & $\mathrm{x}$ & & & $\mathrm{x}$ & & & $\mathrm{x}$ & $\mathrm{x}$ & $\mathrm{x}$ & & & & & \\
\hline Carassius auratus & $\mathrm{x}$ & $\mathrm{x}$ & & & & & & & & & & & & & & & & & & & & \\
\hline Carassius gibelio & $\mathrm{x}$ & $\mathrm{x}$ & & $\mathrm{x}$ & & & & & & & & & & & & & & & & & $\mathrm{x}$ & \\
\hline Cobitis simplicispina & & & & & & & & & & & & & & $\mathrm{x}$ & $\mathrm{x}$ & & & & & & & \\
\hline Cyprinus carpio & $\mathrm{x}$ & $\mathrm{x}$ & $\mathrm{x}$ & $\mathrm{x}$ & $\mathrm{x}$ & & $\mathrm{x}$ & $\mathrm{x}$ & $\mathrm{x}$ & & & & & & & & & & & & & \\
\hline Luciobarbus escherichii* & & & & & & & & & $\mathrm{x}$ & & & & & & & & & & & & & \\
\hline Oreochromis niloticus* & & & & & & $\mathrm{x}$ & & & & & & & & & & & & & & & & \\
\hline Oxynoemacheilus angorae & & & & & & & & & & & & & & $\mathrm{x}$ & $\mathrm{x}$ & $\mathrm{x}$ & $\mathrm{x}$ & $\mathrm{x}$ & & & & \\
\hline Sander lucioperca & & & & & & $\mathrm{x}$ & & & & & & & & & & & & & & & & \\
\hline Seminemacheilus lendlii & & & & & & & & & & & & & & & & & & & & & & $\mathrm{x}$ \\
\hline Silurus glanis* & & & & & & & & & $\mathrm{x}$ & & & & & & & & & & & & & \\
\hline Squalius cf. cephalus & & & $\mathrm{x}$ & & $\mathrm{x}$ & & $\mathrm{x}$ & & $\mathrm{x}$ & $\mathrm{x}$ & $\mathrm{x}$ & $\mathrm{x}$ & $\mathrm{x}$ & $\mathrm{x}$ & $\mathrm{x}$ & $\mathrm{x}$ & $\mathrm{x}$ & & & & $\mathrm{x}$ & \\
\hline Tinca tinca & & & & & & $\mathrm{x}$ & & & & & & & & & & & & & & & & \\
\hline
\end{tabular}

Nevşehir ili ihtiyofaunasını oluşturan türlerin taksonomik kategorileri Eschmeyer ve Fricke’e göre 25 sıralanmış ve bu türlerin bulunurlukları, IUCN kategorileri, koruma öncelikleri ve ekolojik toleransları da literatür bilgilerine dayanarak tespit edilmiştir (Tablo 3). 
Söz konusu 17 türden 7 tanesinin sonradan aşılama yoluyla bölgede yayılış gösteren egzotik türler olduğu, 6 türün geniş yayılışlı ve 4 türün ise (C. tinca, S.lendlii, C. simplicispina ve A. orontis) Türkiye için endemik olduğu belirlenmiştir. IUCN kategorilerine göre (IUCN, 2015); VU olarak belirtilen A. orontis'den 2 birey, endemik tür olan S. lendlii'den 10 birey ve yeni tanımlanmış endemik bir tür olan A. marassantensis'den ise 141 birey örneklenmiştir. Diğer türlerin IUCN kategorileri ise LC olarak belirlenmiştir olup geniş yayılışı ( $S$. cf. cephalus, O. angorae, C. sieboldi, T. tinca) veya istilacı (C. carpio, C. auratus, C. gibelio, S. lucioperca) türlerden oluşmaktadır.

Tablo 3. Nevșehir ilinde tespit edilmiș olan taksonların Latince ve Türkçe isimleri, bulunurlukları, IUCN kategorileri, koruma öncelikleri ve ekolojik toleransları. (*Damsa Barajı'nda 2013 yılında tespit edilmiş; **Doğan (2013) tarafindan rapor edilmiş; *** Mert ve Çiçek (2010) tarafindan rapor edilmiş. I: Așılanmıș; N: Doğal yayılışlı, E: Endemik; LC: Düşük risk, NT: Tehlike sınırında, VU: Hassas, NE: Belirlenmedi; Yok: Korunmasına gerek yok; Düşük: İzlemeye gerek yok; Orta: İzlenmesi önerilir; Yüksek: Mutlak izlenmesi ve korunması gerekli tür; Hassas: Habitatta meydana gelen değissimlerden çabuk etkilenen; Orta: Habitat bozulmalarına karşı dirençli; Yüksek: Habitat bozulmalarına karşı toleransı yüksek)

\begin{tabular}{|c|c|c|c|c|c|}
\hline 胥 & 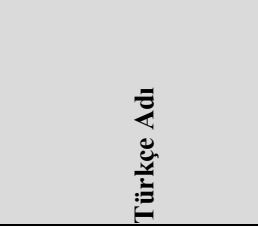 & 总 & Z & 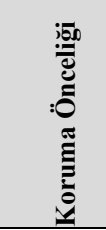 & 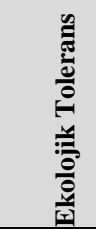 \\
\hline \multicolumn{6}{|l|}{$\begin{array}{l}\text { Order ATHERINIFORMES } \\
\text { Family ATHERINIDAE } \\
\text { Subfamily ATHERININAE }\end{array}$} \\
\hline Atherina boyeri Risso, $1810 *$ & Gümüş balığg & $\mathrm{I}$ & LC & Yok & Yüksek \\
\hline \multicolumn{6}{|l|}{$\begin{array}{l}\text { Order CYPRINIFORMES } \\
\text { Family CYPRINIDAE }\end{array}$} \\
\hline $\begin{array}{l}\text { Capoeta sieboldii (Steindachner, 1864) } \\
\text { Capoeta tinca (Heckel, 1843) }\end{array}$ & $\begin{array}{l}\text { Siraz balığ } \\
\text { Siraz balığ } 1\end{array}$ & $\begin{array}{l}\mathrm{N} \\
\mathrm{N}\end{array}$ & $\begin{array}{l}\mathrm{LC} \\
\mathrm{LC}\end{array}$ & $\begin{array}{l}\text { Düşük } \\
\text { Düşük }\end{array}$ & $\begin{array}{l}\text { Orta } \\
\text { Orta }\end{array}$ \\
\hline \multicolumn{6}{|l|}{ Subfamily BARBINAE } \\
\hline Luciobarbus escherichii (Steindachner, 1897)** & Biyıklı balık & $\mathrm{N}$ & LC & Orta & Hassas \\
\hline \multicolumn{6}{|l|}{ Subfamily CYPRININAE } \\
\hline $\begin{array}{l}\text { Carassius auratus (Linnaeus, 1758) } \\
\text { Carassius gibelio (Bloch, 1782) } \\
\text { Cyprinus carpio (Linnaeus, 1758) }\end{array}$ & $\begin{array}{l}\text { Havuz balığ1 } \\
\text { Havuz balığ } \\
\text { Sazan balığ1 }\end{array}$ & $\begin{array}{l}\mathrm{I} \\
\mathrm{I} \\
\mathrm{I}\end{array}$ & $\begin{array}{l}\mathrm{NE} \\
\mathrm{NE} \\
\mathrm{NE}\end{array}$ & $\begin{array}{l}\text { Yok } \\
\text { Yok } \\
\text { Yok }\end{array}$ & $\begin{array}{l}\text { Yüksek } \\
\text { Yüksek } \\
\text { Yüksek }\end{array}$ \\
\hline \multicolumn{6}{|l|}{ Subfamily TINCINAE } \\
\hline Tinca tinca (Linnaeus, 1758) & Kadife sazan & $\mathrm{I}$ & LC & Düşük & Yüksek \\
\hline \multicolumn{6}{|l|}{ Subfamily LEUCISCINAE } \\
\hline Squalius cf. cephalus (Linnaeus, 1758) & Tatlı su kefali & $\mathrm{N}$ & LC & Düşük & Yüksek \\
\hline \multicolumn{6}{|l|}{ Subfamily ALBURNINAE } \\
\hline Alburnus orontis Sauvage, 1882 & İnci balığ1 & $\mathrm{N}$ & VU & Orta & Hassas \\
\hline \multicolumn{6}{|l|}{$\begin{array}{l}\text { Family CYPRINODONTIDAE } \\
\text { Subfamily CYPRINODONTINAE }\end{array}$} \\
\hline $\begin{array}{l}\text { Aphanius marassantensis Pfleiderer, Geiger \& Herder, } \\
2014\end{array}$ & Dişli sazancık & $\mathrm{E}$ & $\mathrm{NE}$ & Yüksek & Hassas \\
\hline \multicolumn{6}{|l|}{$\begin{array}{l}\text { Family COBITIDAE } \\
\text { Subfamily COBITINAE }\end{array}$} \\
\hline Cobitis simplicispina Hanko, 1925 & Çöpçü balığ 1 & $\mathrm{E}$ & LC & Orta & Orta \\
\hline \multicolumn{6}{|l|}{ Family NEMACHEILIDAE } \\
\hline $\begin{array}{l}\text { Seminemacheilus lendlii Hanko, } 1925 \\
\text { Oxynoemacheilus angorae (Steindachner, 1897) }\end{array}$ & $\begin{array}{l}\text { Çöpçü balığ1 } \\
\text { Çöpçü balığ1 }\end{array}$ & $\begin{array}{l}\mathrm{E} \\
\mathrm{E}\end{array}$ & $\begin{array}{l}\mathrm{NE} \\
\mathrm{LC}\end{array}$ & $\begin{array}{l}\text { Orta } \\
\text { Orta }\end{array}$ & $\begin{array}{l}\text { Orta } \\
\text { Orta }\end{array}$ \\
\hline $\begin{array}{l}\text { Order PERCIFORMES } \\
\text { Family PERCIDAE } \\
\text { Subfamily LUCIOPERCINAE }\end{array}$ & & & & & \\
\hline Sander lucioperca (Linnaeus, 1758) & Sudak, tatlı su levreği & I & LC & Düşük & Hassas \\
\hline $\begin{array}{l}\text { Family CICLIDAE } \\
\text { Subfamily PSEUDOCRENILABRINAE }\end{array}$ & & & & & \\
\hline Oreochromis niloticus (Linnaeus, 1758)*** & Tilapya & I & $\mathrm{NE}$ & Yok & Yüksek \\
\hline \multicolumn{6}{|l|}{$\begin{array}{l}\text { Order SILURIFORMES } \\
\text { Family SILURIDAE }\end{array}$} \\
\hline Silurus glanis Linnaeus, $1758^{* *}$ & Yayın & $\mathrm{N}$ & LC & Orta & Orta \\
\hline
\end{tabular}


S. glanis ve L. escherichii Kızılırmak’ta dağılım gösteren türlerdir [21]. Kızılırmak üzerinde inşa edilmiş barajlar ve HES'ler nedeniyle nehirdeki su rejimi tamamen değişmiş, akıntı hızı azalmış, su içi bitkilenme oranında artış görülmüş, suyun yenilenme hızı azaldığından kirlilik emareleri ortaya çıkmıştır. L. escherichii türünün temiz, akıntılı ve zemin yapısı taşlı, çakıllı habitatları tercih ettiği bilinmektedir. Kızılırmak'ta meydana gelen bu değişimler nedeniyle bu türün muhtemelen çok seyrek olarak bulunduğu ve bu nedenle de bu çalışma sırasında yakalanamadığı iddia edilebilir. Avlanması zor ve düşük yoğunluğa sahip bir olan S. glanis'in de Kızılırmakta meydana gelen habitat değişikliklerinden etkilenmiş olabileceği veya düşük popülasyon yoğunluğu nedeniyle ve avlanmasının biraz zor olması nedeniyle avlanamamış olabileceği iddia edilebilir. Daha önce Damsa Barajında rastlanmış olan O. niloticus [20] ve A. boyeri türlerinin ise ortam koşullarına uyum sağlayamayarak yok oldukları için tespit edilemedikleri düşünülmektedir.

Ayrıca proje çalışması süresince örneklemenin tek bir defa yapılmış olması nedeniyle bazı türlerin bu çalışmada elde edilememesine sebep olduğu düşünülmektedir.

\subsection{Koruma Öncelikli Taksonlar ve İzleme Planı}

Nevşehir ilinde yayılış gösteren taksonlardan IUCN kategorileri, korunma öncelikleri ve ekolojik toleransları göz önüne alındığında, VU olan A. orontis ve S. lendlii ile NT olan A. marassantensis türleri ile endemik bir tür olan $C$. simplicispina türünün öncelikle korunması gereken taksonlar olarak düşünülebilir (Tablo 3).

A. orontis kirliliğe karşı toleransı düşük olan bir tür olup habitat kaybına bağlı olarak populasyon büyüklüğünde azalış ve dağılım alanında daralmalar görülmeye başlanmıştır.

A. marassantensis temiz sulak alan sistemlerinde rastlanması ve sulak alan ekosistemi açısından, özellikle pek çok türün besinini oluşturması sebebiyle, ekolojik öneme sahip bir türdür. Habitat kaybı ve kirlilik, türü tehdit eden önemli faktörlerdir.

Demersal türlerden olan $C$. simplicispina ve $S$. lendlii ise bentik bölgede, kumlu, çamurlu yumuşak zeminlerde dağılım göstermektedirler. Bu nedenle gerek kirlilik, gerek sediment yapısındaki bozulmalar ve gerekse su rejimindeki değişikliklere karşı oldukça hassas bir türdür.

Yukarıda bahsi geçen türlerin yılda bir defa izlenerek üreme başarısına bağlı olarak popülasyonun durumunun değerlendirilmesi önerilmektedir.

\subsection{Biyolojik Çeşitliliğe İlişkin Tehditler}

İç sularımızdaki biyoçeşitliliği tehdit eden başlıca unsurlar; kirlilik, habitat tahribi ve/veya kaybı, su rejimine yapılan bilinçsiz müdahaleler, istilacı türler, aşırı avcılık ve iklim koşullarındaki değişimler olarak sıralanabilir. Nevşehir ili için de benzer tehditlerden bahsetmek mümkündür.

Arazi çalışmaları sonucunda Nevşehir'de tatlı su kaynaklarının oldukça daralmış olduğu ve mevcut kaynakların genellikle tarımsal sulama gibi amaçlarla önlerine bentler kurulduğu, bunun yanı sıra kirlilik tehdidi altında olduğu gözlemlenmiştir. İl içinde kısıtlı olan akarsu kaynaklarının düzensiz ve bilinçsiz kullanımı ile su rejiminde değişiklikler oluşmakta bu da habitat kaybı ile sonuçlanmaktadır. Arıtım yapılmadan deşarj edilen evsel ve zirai atık sular kirliliğe ve ötrofik ortamlar oluşmasına sebep olmaktadır. Ötrofikasyonun ise besin zincirinde değişiklikler meydana gelmesine ve su kalitesinin de 
bozulmasına ve sonunda su kütlesinin kaybına kadar varabilen ciddi sorunlara yol açabildiği uzun yıllardır gözlemlenmektedir. Zirai gübre ve ilaç gibi girdilerin aşırı kullanımı ile evsel ve endüstriyel atıklar iç suların kirlenmesine neden olmaktadır. Evsel atık suların ötrofikasyona neden olarak hem akarsu hem de baraj göllerinde ciddi tehditler oluşturduğu ve buna bağlı olarak 2012, 2013 ve 2014 yıllarının yaz aylarında Kızılırmak Nehri ve Tatlarin Barajında toplu balık ölümlerine sebep olduğu yapılan arazi çalışmalarımızda tespit edilmiştir.

Nevşehir'deki balık türleri için özellikle barajlarda görülen bir diğer tehdit de istilacı türlerdir. Çeşitli amaçlarla ekosistemlerimize aşılama yoluyla bırakılan bu türler ekosistemdeki olumsuz koşullara olan yüksek toleransları, yüksek üreme başarısı gibi nedenler ile habitatta baskın tür olarak öne çıkmaktadırlar. C. auratus, C. gibelio ve C. carpio gibi istilacı türler yerli türlerin dağılımını tehdit etmekte ve yaşam alanlarını kısıtlayıcı bir etki oluşturmaktadır. Nitekim Tatlarin ve Yalıntaş barajlarında istilacı türlerin ekosistemin dengesini kendi lehlerine bozdukları ve hiçbir yerli türün yaşamasına olanak tanımadıkları tespit edilmiştir. Bu barajlarda kirlilik yükünün artması toleransı düşük yerli türlerin yok olmasına sebep olurken geniş toleransa sahip istilacı türlerin nişlerini genişletmelerine yardımcı olmaktadır.

Egzotik türlerin istilacı özellik sergilediği göz önüne alındığında, bu türlerin popülasyon yapısının belirlenmesi ve mevsimlik örneklemeler yapılarak izlenmesi gerektiği ortaya çıkmaktadır. Ayrıca ildeki barajların bazılarında istilacı türlerin henüz bulunmadığı tespit edilmiştir. Bundan sonra ilde yapılacak olan balıklandırma çalışmalarında dikkatli olunması ve yeni egzotik türlerin girişinin önlenmesi büyük önem taşımaktadır.

Damsa Barajında 2013 yılı kış aylarında görülen toplu balık ölümlerinde A. boyeri türüne rastlanmıştır. Bu türün ortam koşullarına uyum sağlayamaması sonucu öldükleri tespit edilmiş olup şu anda bu türe ait bir popülasyon bulunmamaktadır. Ancak söz konusu türün muhtemelen balıklandırma yoluyla istenmeden taşınmış olduğu düşünüldüğünde, ileriki yıllarda yapılacak aşılamalarla tekrar bölge sularına girmesinin söz konusu olabileceği iddia edilebilir.

\section{Sonuç ve Öneriler}

Arazi çalışmalarında haritalarda yer alan su kaynaklarının bir kısmının tamamen kurumuş olduğu görülmüştür. Bunun yanı sıra, evsel, tarımsal ve endüstriyel kirlilik, su rejimindeki değişiklik yapılması vb. gibi nedenlerle habitat kaybının söz konusu olduğu, balıkların yaşamasına uygun koşullara sahip olmadıkları tespit edilmiştir. Bu nedenle izlenmeye konu türlerin populasyonlarının korunması için tehdit unsurlarının belirlenmesi, kontrol altında tutulması ve habitatların iyileştirilmesine yönelik olarak önlemler alınması büyük önem taşımaktadır.

Bunun yanı sıra biyoçeşitliliğgin korunması açısından ildeki barajlarda bulunan istilacı balık türleri ile ilgili izleme yapılması gerektiği düşünülmektedir. Bu türlerin durumlarının belirlenmesi, yeni habitatlara yayılmalarının engellenmesi ve yol açabilecekleri olumsuz etkilerin önüne geçilebilmesi için önlemler alınması gerekmektedir.

Ayrıca izleme çalışmaları sırasında periyodik gözlemler ile envanter çalışmasında belirlenmiş olan taksonların durumu ve populasyon yoğunlukları, taksonların ekolojik tolerans seviyeleri ve habitat seçimleri, ekosistem üzerinde yarattıkları değişikliklerin izlenmesi önerilmektedir. 
Sonuç olarak Nevşehir ili biyoçeşitliliğinin uzun vadede korunabilmesi ve sürdürülebilirliğinin sağlanması açısından tehdit unsurlarının belirlenmesi ve gerekli önlemlerin alınması için konunun uzmanları ile ilgili kuruluşlar birlikte hareket ederek eylem planları oluşturulmalıdır.

\section{Teșekkür}

$\mathrm{Bu}$ çalışmanın yürütülmesini sağlayan Orman ve Su İşleri Bakanlığı, Doğa Koruma ve Milli Parklar Genel Müdürlüğüne, yardım ve işbirlikleri için Nevşehir İl Şube Müdürü Erol Aksoy ve diğer teşkilat mensuplarına ve desteklerinden dolayı Eko-Zon Halk Sağlığı ve Çevre Danışmanlığı'na teşekkür ederiz.

\section{Kaynaklar}

[1] Anonim, Ulusal Biyolojik Çeşitlilik Stratejisi ve Eylem Planı. T.C. Çevre ve Orman Bakanlığı, Doğa Koruma ve Milli Parklar Genel Müdürlüğü, Doğa Koruma Dairesi Başkanlığı, Ankara, 176, 2007.

[2] Demirsoy, A., “Genel Zoocoğrafya ve Türkiye Zoocoğrafyası "Hayvan Coğrafyası”.Yedinci Bask1. Ankara. Meteksan A.Ş. ,1007, 2008.

[3] Özuslu, E., Tel, A.Z., Kaya, A., Avcı, A., Ilgaz, Ç., Yağmur, E.A., İzler, F., Koç, H., Toprak, H.H.C., Sevgili, H., Toyran, K., Öztekin, M., Kırmacı, M., Üzüm, N., Kaya, R., Birecikligil, S.S., Bozacı, V., “Gaziantep’in Biyolojik Çeşitliliği” Doğa Koruma Derneği Yayınları, Gaziantep, 2011.

[4] Tarkan, A.S., Marr, S.M., Ekmekçi, F.G., "Non-native and translocated freshwater fish species in Turkey”, Fishes in Mediterranean Environments 2015.003: 28, 2015.

[5] Çiçek, E., Birecikligil, S., Fricke, R., "Revised and updated annotated checklist of the freshwater fishes of Turkey”, 2. Zooloji Kongresi, 28-31 Ağustos 2015, Afyonkarahisar, 2015.

[6] Kence, A., Bilgin, C.C. “Türkiye Omurgalılar Tür Listesi”, Ankara. Nurol Matbaacılık, 1996.

[7] Geldiay, R., Balık, S., Türkiye Tatlısu Balıkları. V. Baskı. İzmir. Ege Üniversitesi Su Ürünleri Fakültesi Yayınları. 532 2007..

[8] Abbott, K.E., “Letter accompanying a Collection from Trebizond and Erzeroun” Proceedings of the Zoological Society of London, 3, 89-92, 1835.

[9] Richardson, J., “On Some Fishes from Asia Minor and Palestine”. Proc. Zool. Soc. London tome, 24, 371-377, 1856.

[10] Deyrolle, M.T., Notice sur une Espece Remarquable de Poisson qui vit Dans les eaux du lac de van. Rev. Et. Mag. De Zoologie, 401-406, 1872.

[11] Gaillard, P.C., "Notes sur Quelques Especes de Cyprinodons de L'asie Mineure et de la Syrie”, Archive of Museum History Lyon, 6, 1-15, 1895.

[12] Boulenger, G.A., “On Freshwater Fishes from Smyrna”. The Annals and Magazine of Natural History, 153-154, 1896.

[13] Steindachner, F., "Bericht über die von Dr. Escherich in der Umgebung von Angora Gesammelten Fische und Reptilien”, Denkschr. Sitzungsberichte der Kaiserliche Akademie der Wissenschaften in Wien, 64, 685-699, 1897. 
[14] Hanko, B., "Fische aus Klein-Asien”, The Annals and Magazine of Natural History, 21, 137$158,1924$.

[15] Neu, W., "Burdur Gölü’nden Çıkan Cyprinodon sureyanus n. sp.” İstanbul Üniversitesi Fen Fakültesi Mecmuas1, II, 109-113,1937.

[16] Kosswig, C., "Türkiye Tatlı Su Balıklarının Zoocoğrafyası”, İstanbul Üniversitesi Fen Fakültesi Hidrobioloji Araştırma Enstitüsü Mecmuası, 1-19, 1954.

[17] Ladiges, W.V., "Süßwasserfische der Türkei, I. Teil.: Cyprinidae”, Mitteilungen aus dem Hamburgischen Zoologischen Museum und Institut, 58, 105-150, 1960.

[18] Bilecenoğlu, M., Kaya, M., Cihangir, B., Çiçek, E., "An updated checklist of the marine fishes of Turkey.” Turkish Journal of Zoology, 38: 901-929, 2014.

[19] Pfleiderer, S.J., Geiger, M.F., Herder, F., "Aphanius marassantensis, a new toothcarp from the Kızllırmak drainage in northern Anatolia (Cyprinodontiformes: Cyprinodontidae)", Zootaxa, 3887, 569-82, 2014.

[20] Polat, N., Uğurlu, S., Kandemir, Ş., "Aşağı Kızılırmak Havzası (Samsun-Türkiye) Balık Faunası” Journal of Fisheries Sciences, 2 (3):489-498, 2008.

[21] Doğan, A., "Kızılırmak Nehri (Nevşehir), Ayhanlar, Damsa ve Tatlarin Baraj Gölleri Balık Faunasının Belirlenmesi” Nevşehir Hacı Bektaş Veli Üniversitesi, Fen Bilimleri Enstitüsü. Yüksek Lisans Tezi. Nevşehir., 2013.

[22] Mert, R., Çiçek, E., "Range Expansion of Introduced Tilapia Species (Oreochromis niloticus, L. 1758, Cichlidae) in Turkey” Journal of Animal and Veterinary Advences, 9: 1753-1756, 2010.

[23] Kottelat M., Freyhof J., "Handbook of European Freshwater Fishes. Switzerlan”d. Imprimerie du Démocrate SA, Delémont, 2007.

[24] Coad, B.W., "Freshwater Fishes of Iran”. Canadian Museum of Nature, Ottawa, Ontario, Canada. www.briancoad.com, 2014.

[25] Eschmeyer, W. N. and Fricke, R. (eds). "Catalog of Fishes: Genera, Species", References(http://researcharchive.calacademy.org/research/ichthyology/catalog/fishcatmain.asp) . Electronic version accessed 14/10/2015. [This version was edited by Bill Eschmeyer.]

[26] IUCN 2015. IUCN Red List of Threatened Species. Version 2014.3. <www.iucnredlist.org>. Downloaded on 12 March 2015. 